\title{
Salt intakes in patients with gastro-oesophageal reflux disease
}

\author{
Michelle L. Hawkins ${ }^{1}$, Gloria J. Davies ${ }^{1}$, Martin F. Chaplin ${ }^{1}$, John Dillon ${ }^{2}$ and Peter Dettmar ${ }^{3}$ \\ ${ }^{1}$ London South Bank University, London, UK, ${ }^{2}$ Ninewells Hospital, Dundee, UK and ${ }^{3}$ Technostics, Hull, UK
}

Gastro-oesophageal reflux disease (GORD) is a risk factor for Barrett's oesophagus (BO), a precursor condition for oesophageal adenocarcinoma (OA). Scotland has the highest incidence of OA in Europe ${ }^{(1)}$, its population also has the highest salt intakes in the UK ${ }^{(2,3)}$. Norwegian data suggests that there may be a relationship between a high salt intake and GORD ${ }^{(4)}$.

The aim of the present study was to investigate possible differences in dietary intakes of salt in three groups of patients. Those diagnosed with non-erosive reflux disease (NERD), erosive reflux disease (ERD) and BO, were recruited from the Gastroenterology Clinic at Ninewells Hospital, Dundee. Ethical approval was given by the Tayside Research Ethics Committee. A total of 102 patients completed a $7 \mathrm{~d}$ estimated diet record, patients were asked to record salt added during cooking and at the table. Salt intakes were estimated from Na intakes using Dietplan 6 (Forestfield Software Ltd, Horsham, West Sussex, UK). Salt intakes were compared with dietary recommendations $^{(5)}$.

\begin{tabular}{|c|c|c|c|c|c|c|}
\hline & \multicolumn{2}{|c|}{ NERD (n 47) } & \multicolumn{2}{|c|}{ ERD (n 23) } & \multicolumn{2}{|c|}{$\mathrm{BO}$ (n 32) } \\
\hline & $\mathrm{M}(n$ 21) & $\mathrm{F}(n 26)$ & $\mathrm{M}(n 11)$ & $\mathrm{F}(n$ 12) & $\mathrm{M}(n 19)$ & $\mathrm{F}(n-13)$ \\
\hline \multicolumn{7}{|c|}{ Salt intake $(\mathrm{g} / \mathrm{d})$ : } \\
\hline Mean & 8.8 & 6.4 & 8.0 & 6.3 & 7.7 & 5.9 \\
\hline Range & $5.5-15.8$ & $3.5-9.8$ & $6.0-14.0$ & $4.3-13.5$ & $5.0-9.5$ & $3.0-8.8$ \\
\hline \multicolumn{7}{|l|}{$\%$ Patients } \\
\hline$>6 \mathrm{~g}$ salt $/ \mathrm{d}$ & 81 & 54 & 82 & 42 & 84 & 38 \\
\hline
\end{tabular}

M, males; F, females.

For each condition the mean intake of salt was higher for males than for females. There was no correlation between salt intake and either BMI or total dietary intake. Salt intakes for both genders in each patient group were wide ranging. In each condition a higher percentage of males compared with females had intakes $>6 \mathrm{~g} / \mathrm{d}(\mathrm{Z}$ test; $P<0.05)$. The differences in salt intakes for both male and female patients are possibly related to the male bias in the prevalence of ERD and $\mathrm{BO}^{(6,7)}$. These findings are in accord with the suggestion that salt may be a risk factor for $\mathrm{GORD}^{(4)}$.

1. Misra N \& Hardwick RH (2004) Gut 53, Suppl. III, A60.

2. Henderson L, Irving K \& Gregory J (2002) The National Diet and Nutrition Survey: Adults Aged 19 to 64 Years. vol. 3: Vitamin and Mineral and Urinary Analytes. London: The Stationery Office.

3. Finch S, Doyle W, Lowe C, Bates C, Prentice A, Smithers G \& Clarke PC (1998) The National Diet and Nutrition Survey: People Aged 65 Years and Over. vol. 1: Report of the Diet and Nutrition Survey. London: The Stationery Office.

4. Nilsson M, Johnsen R, Ye W, Hveem K \& Lagergren J (2004) Gut 53, 1730-1735.

5. Scientific Advisory Committee on Nutrition (2003) Salt and Health. London: The Stationery Office.

6. Gerson LB, Edson R, Lavori PW \& Triadafilopoulos G (2001) Am J Gastroenterol 96, 2005-2012.

7. Watson A \& Caygill CP (2002) Gastroenterology 122, Suppl., A350. 